\title{
Barreiras à realização do exame Papanicolau: perspectivas de usuárias e profissionais da Estratégia de Saúde da Família da cidade de Vitória da Conquista-BA
}

| ${ }^{1}$ Rebeca Pinheiro Aguilar, ${ }^{2}$ Daniela Arruda Soares |

Resumo: O câncer de colo uterino apresenta altas taxas de prevalência e mortalidade, e a principal estratégia para seu rastreamento é o exame Papanicolau. A adesão ao exame ainda está distante da cobertura preconizada. Objetivou-se conhecer as barreiras que levam mulheres em idade fértil da cidade de Vitória da Conquista-BA a não realizarem o exame Papanicolau, na perspectiva das próprias mulheres e dos profissionais de saúde. Estudo descritivo, exploratório qualitativo, com dados coletados entre abril a maio de 2014, com entrevista semiestruturada aplicada a 12 profissionais e 14 usuárias. Foi aplicada análise categorial temática, que revelou as seguintes barreiras para não realização do exame: conhecimento insuficiente, sentimentos negativos, falta de atitude, aspectos vinculados aos serviços de saúde e inserção da mulher no mercado de trabalho. A congruência e incongruência de significados emergidos possibilitarão um caminho que transforme a prática do profissional de saúde e atendimento das necessidades dessas mulheres.

> Palavras-chave: esfregaço vaginal; doenças do colo do útero; saúde da família.

\author{
1 Universidade Federal da Bahia. \\ Vitória da Conquista-BA, Brasil. \\ Endereço eletrônico: \\ rebeca.aguilar7@gmail.com \\ ${ }^{2}$ Universidade Federal da Bahia \\ Vitória da Conquista-BA, \\ Brasil. Endereço eletrônico: \\ dandani23@yahoo.com.br
}

Recebido em: 07/08/2014 Aprovado em: 23/02/2015 
O câncer do colo uterino é considerado um importante problema de saúde pública que atinge todas as classes sociais e regiōes geoeconômicas do país, embora indícios apontem maior acometimento entre mulheres de pior nível socioeconômico e com dificuldades de acesso aos serviços de saúde (AMORIM et al., 2006; BRENNA et al., 2001). Apresenta-se como a segunda neoplasia maligna mais comum entre as mulheres no mundo, sendo responsável por aproximadamente 471 mil casos novos e por cerca de 230 mil óbitos de mulheres por ano (DAVIM et al., 2005). É o segundo tumor mais diagnosticado em mulheres no Brasil, apesar de possuir alto potencial de prevenção (RICO; IRIART, 2013).

O Ministério da Saúde preconiza como grupo prioritário para realização do exame de rastreamento do câncer de colo do útero (Papanicolau) mulheres entre 25 e 64 anos; entretanto, a incidência desse tipo de câncer no Brasil é evidenciada a partir dos 20-29 anos, estando o maior risco na faixa etária de 45-49 anos (RICO; IRIART, 2013).

Os países em desenvolvimento são os que apresentam maiores taxas de incidência, com número aproximado de $80 \%$. No Brasil, segundo estimativas nacionais, cerca de seis milhões de mulheres entre 35 e 49 anos nunca realizaram o exame Papanicolau (BRASIL, 2002). Considerando que nesta faixa etária ocorre maior número de casos positivos de câncer do colo do útero, a não realização do exame, por parte das mulheres elegíveis, obstaculiza açôes de saúde de caráter promotor, preventivo e assistencial visando ao rastreamento, diagnóstico precoce e tratamento adequado. Tal situação concorre para o diagnóstico do câncer cérvico-uterino em estágios avançados, com menor sobrevida média quando comparada a dos países desenvolvidos (CRUZ; LOUREIRO, 2008).

O exame Papanicolau consiste no esfregaço de células oriundas da ectocérvice e da endocérvice, que são extraídas por raspagem do colo do útero. Embora ele represente o instrumento mais adequado, prático e de baixo custo para o rastreamento do câncer de colo de útero, devido à forte influência na redução da morbi-mortalidade por este tipo de câncer, a adesão ao exame ainda está distante da cobertura preconizada pelo Ministério da Saúde, que é de 80 a 85\% (OLIVEIRA et al., 2006). 
No ano de 2012, a população feminina entre 25 e 59 anos residente em Vitória da Conquista-BA era de 76.921 mulheres, das quais apenas 11,6\% realizaram o exame Papanicolau (SISCOLO, 2012). Dentre as razões para a não realização desse exame no país, destacam-se: a representação e o conhecimento acerca da doença, presença de pudores, tabus, medo, a dificuldade no acesso aos serviços de saúde e a qualidade dos mesmos, além de condiçóes socioeconômicas e culturais (FERNANDES et al., 2009; RICO; IRIART, 2013; SOUSA et al., 2008). Neste sentido, faz-se necessário reconhecer o universo simbólico que o câncer cérvico-uterino e o exame Papanicolau têm para as mulheres, a fim de subsidiar a atuação do profissional de saúde quanto à realização do exame, no sentido de implementar estratégias com vistas à detecção precoce da doença e, por conseguinte, a melhoria da qualidade de vida das mulheres.

Face ao exposto, emergiu a necessidade de responder às seguintes questôes norteadoras: quais as barreiras que levam mulheres em idade fértil a nunca realizarem o exame Papanicolau na cidade de Vitória da Conquista-BA? Qual a percepção de profissionais de saúde que atuam na Estratégia de Saúde da Família (ESF) acerca dessas barreiras? Na tentativa de responder aos questionamentos supracitados, o seguinte objetivo foi delineado: conhecer as barreiras que levam mulheres em idade fértil da cidade de Vitória da Conquista-BA a não realizarem o exame Papanicolau na perspectiva delas próprias e dos profissionais de saúde.

\section{Metodologia}

Tratou-se de estudo descritivo e exploratório com abordagem qualitativa, mediante o qual se buscou conhecer em profundidade o rico potencial das percepçóes e subjetividades de mulheres e profissionais, acerca das barreiras que interferem na realização do exame Papanicolau. Foi realizado no município de Vitória da Conquista-BA, localizado na região Sudoeste do Estado da Bahia, distante503 Km da capital Salvador, que conta com 42 equipes de saúde da família, sendo 25 na zona urbana e 17 na zona rural.

A coleta de dados foi realizada durante os meses de abril a maio de 2014, em seis unidades de saúde da família, as quais foram selecionadas aleatoriamente, obedecendo aos seguintes critérios: estar localizada na zona urbana do município, 
devido à maior facilidade de acesso; possuir o Programa de Educação pelo Trabalho-Saúde (PET-Saúde), uma vez que esta estratégia do Ministério da Saúde visa fomentar grupos de aprendizagem tutorial em áreas estratégicas para o serviço público de saúde, caracterizando-se como instrumento para qualificação e fortalecimento da atenção básica em saúde. Tal estratégia estabelece relações entre as instituiçõoes de ensino de nível superior e os serviçosde saúde, de forma buscar maior adesão da população aos programas de saúde (NUNES et al., 2012).

Os sujeitos do estudo foram 12 profissionais e 14 usuárias da ESF. Os critérios de inclusão para usuárias foram: ter idade entre 18 e 49 anos na época da entrevista; nunca ter realizado o exame Papanicolau; e ser cadastrada em uma das unidades onde foi realizada a pesquisa. No que diz respeito aos profissionais de saúde que participaram do estudo, delimitou-se como critério de inclusão: profissionais de saúde que realizam o exame Papanicolau na ESF (enfermeiro, médico); ter pelo menos um ano de atuação na unidade de saúde da família, visto que este tempo mínimo é necessário para a constituição de vínculo entre profissionais da ESF e a comunidade adscrita.

O quantitativo de depoentes considerou o critério de saturação teórica, o qual é definido como a interrupção da coleta de novos participantes, quando os dados obtidos apresentam-se redundantes, não trazendo maiores contribuições para o aprimoramento da reflexão teórica (FONTANELA; RICAS; TURATO, 2008).

As mulheres que participaram do estudo foram identificadas previamente através do agente comunitário de saúde (ACS), por meio da ficha B de mulheres em idade fértil, e foram abordadas em seus domicílios. Os profissionais que participaram da pesquisa foram abordados nas unidades de saúde da família (USF) selecionadas. As entrevistas foram gravadas em dias úteis, tanto no turno matutino quanto no vespertino, e posteriormente transcritas para análise.

Utilizou-se a entrevista semiestruturada como técnica para captação dos dados. O referido instrumento contemplou elementos sociodemográficos específicos para usuárias e profissionais, bem como perguntas abertas, em que os sujeitos tiveram a oportunidade de discorrer sobre o tema, abordando aspectos como motivos para não realização do exame Papanicolau. As entrevistas tiveram duração entre oito a 15 minutos.As mulheres foram identificadas no estudo através da letra U, representando o termo "usuárias", e os profissionais de saúde, 
através da letra $\mathrm{P}$, representando "profissionais", ambas seguidas de um número que foi estabelecido de acordo com a ordem das entrevistas realizadas.

Para análise dos dados produzidos, utilizou-se a técnica de análise de conteúdo do tipo categorial temática, a qual se iniciou com a escuta das entrevistas, seguida de sua transcrição na íntegra. Após a transcrição, foi percorrido o caminho metodológico proposto por Minayo, o qual pressupóe algumas etapas, como: pré-análise, que consistiu na escolha dos documentos analisados e na retomada dos objetivos da pesquisa. Nesta etapa, ocorreu a leitura superficial do material, seguida pela leitura exaustiva e repetida do mesmo na busca de padrões reiterados e contradições para elaboração de uma primeira classificação; exploração do material, que consistiu na aplicação de procedimentos de codificação, classificação e categorização, momento em que os núcleos temáticos e categorias foram instituídos com base nas repetições de temas presentes nas respostas das entrevistadas, favorecendo os agrupamentos analógicos; tratamento dos resultados obtidos e interpretação, momento de reflexão com embasamento nos materiais empíricos, para o estabelecimento de relações e conexões entre as ideias à luz do referencial adotado (MINAYO, 2007).

Todos os sujeitos aceitaram espontaneamente participar e assim foram solicitados a assinar o Termo de Consentimento Livre e Esclarecido, em cumprimento aos princípios éticos da pesquisa com seres humanos, segundo aResolução n ${ }^{\circ}$ 466/2012 do Conselho Nacional de Saúde, Ministério da Saúde, garantindo assim o sigilo, anonimato, liberdade de recusa ou retirada do consentimento em qualquer fase do estudo. O projeto foi aprovado pelo Polo de Educação Permanente da Secretaria Municipal de Saúde do Município de Vitória da Conquista, e pelo Comitê de Ética e Pesquisa do Instituto Multidisciplinar em Saúde - Campus Anísio Teixeira, segundo parecer no 616.205. Também foi solicitada a permissão dos sujeitos para gravação das entrevistas, mediante assinatura do Termo de Autorização do Uso de Imagens e Depoimentos.

\section{Resultados e discussão}

Em relação aos dados sociodemográficos referentes às mulheres entrevistadas, evidenciou-se que a maior parte tinha idade entre 18 e 28 anos; metade possuía 
ensino fundamental incompleto, cerca de $65 \%$ possuíam renda mensal igual ou inferior a um salário mínimo, número equivalente de mulheres frequentou a unidade por período de 1-5 anos e 11-15 anos, cerca de $72 \%$ iniciaram a atividade sexual com idade menor ou igual a 18 anos; $64,2 \%$ não utilizavam nenhum método contraceptivo e grande parte referiu possuir apenas um parceiro sexual no último ano.

Entre os profissionais de saúde entrevistados, todos eram do sexo feminino, sendo que nove eram enfermeiras e três eram médicas. No que diz respeito à idade, metade tinha entre 36 e 45 anos. Quanto ao grau de escolaridade, apenas uma possuía ensino superior sem especialização, sendo que em mais da metade a especialização era em Saúde da família. Em se tratando do tempo de atuação na unidade de saúde da família, $75 \%$ possuíam de um a cinco anos.

A análise do conteúdo das falas das mulheres e dos profissionais de saúde participantes do estudo acerca das barreiras que interferem na realização do exame Papanicolau viabilizou a emergência de um núcleo temático denominado "Barreiras encontradas por mulheres na realização do Papanicolau". O agrupamento das categorias analíticas dentro do núcleo temático evidenciou que as percepções dos dois grupos avaliados foram semelhantes em diversos aspectos, como se pode observar na figura 1. Contudo, surgiram também contradições nas percepções intergrupos, tal como será discutido adiante.

Ressalta-se ainda que a figura condensadora das categorias analíticas desse núcleo temático aponta uma multifatorialidade de elementos limitantes para a realização do Papanicolau vinculados ao conhecimento insuficiente, crenças e tabus das mulheres, falta de atitude das mesmas, sentimentos negativos, como medo e constrangimento, inserção no mercado de trabalho, assim como aspectos relacionados aos serviços de saúde. Denota ainda que a relação entre os elementos contidos nas categorias não ocorre apenas de forma linearizada, mas em múltiplos sentidos, já que falas reiteradas de profissionais e de mulheres usuárias foram encontradas em diferentes categorias, tornando evidente que a interação e interdependência dessas barreiras vão interferir sinergicamente no processo de adesão à realização do exame Papanicolau. 


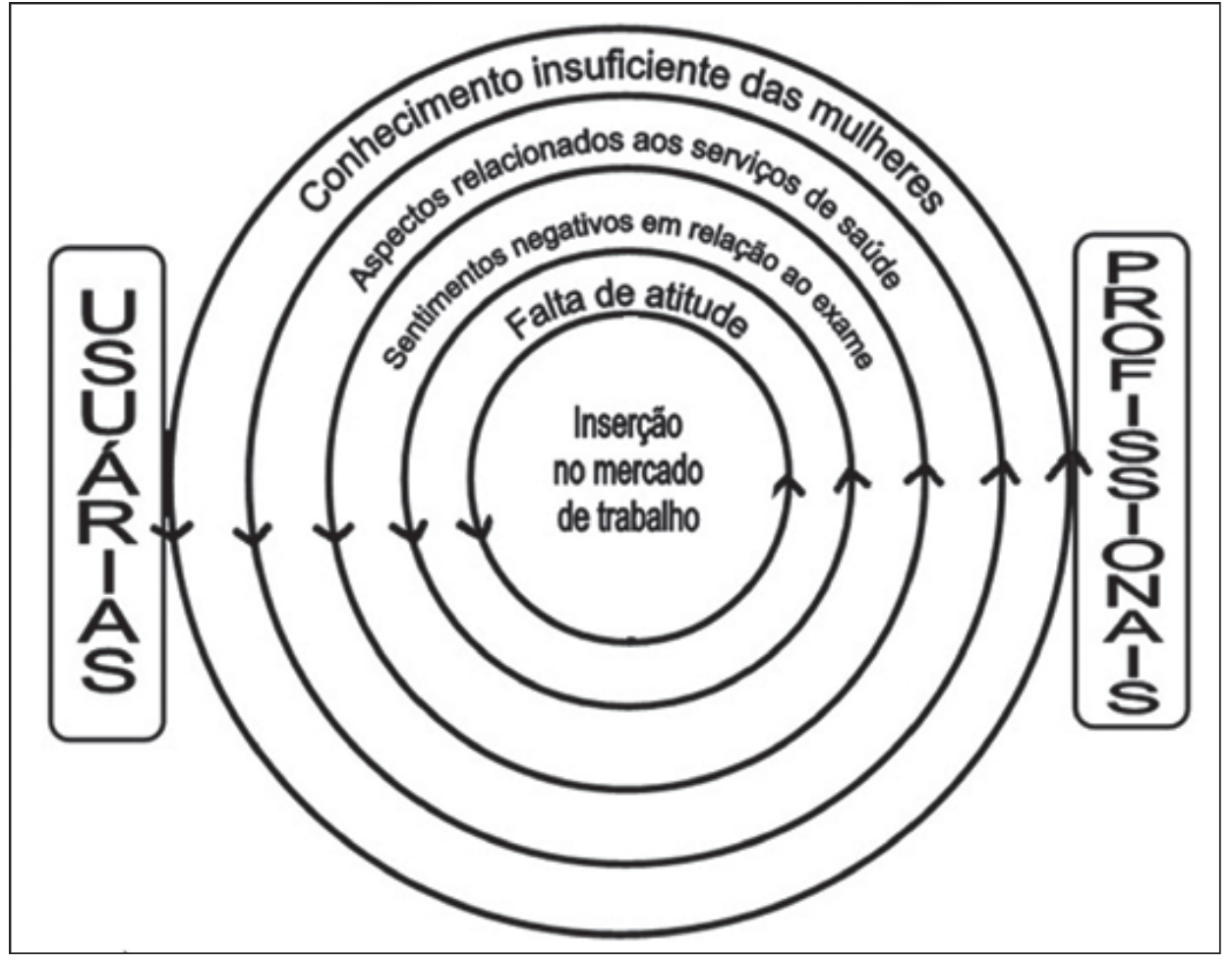

Categoria 1: Conhecimento insuficiente

das mulheres acerca do exame Papanicolau

A literatura é pródiga em sinalizar que a desinformação, o conhecimento errôneo ou insuficiente constituem barreiras à realização de medidas preventivas para o câncer de colo de útero, como a realização do Papanicolau (JORGE et al., 2011; MENDONÇA et al., 2011; OLIVEIRA; PINTO, 2007; RICO; IRIART, 2013; SOUSA et al., 2008). Ademais, o baixo nível socioeconômico das mulheres entrevistadas também contribui para tal situação, pois à medida que diminui o nível socioeconômico, aumenta significativamente a prevalência de mulheres sem cobertura pelo exame Papanicolau (JORGE et al., 2011; LUCENA, 2011). 
O déficit de conhecimento das mulheres acerca do exame Papanicolau pode ser observado a partir das falas das entrevistadas que se seguem.

Eu acho que o exame preventivo serve para descobrir algumas doenças, né? [...](U01).

Eu não conheço o exame, pois nunca fiz, mas eu sei que serve para não criar coisa no útero, né? Não criar bactérias [...] (U09).

Apesar de o câncer de colo uterino apresentar altos potenciais de prevenção por meio do rastreio oportunístico, ainda existem mulheres que desenvolvem e morrem por este tipo de câncer no Brasil, pelo fato de desconhecerem a finalidade do Papanicolau (SILVA et al., 2010). Ao desconhecerem a importância de realizar o exame, as mulheres tendem a não associá-lo a uma prática de saúde.

Os profissionais de saúde também ratificaram, em suas falas, que o conhecimento insuficiente representa uma das barreiras que impedem as mulheres de realizarem o Papanicolau, como pode ser observado nas falas a seguir:

[...] muitas desconhecem a principal causa para realização do exame preventivo [...] elas acham que é para prevenir DST [...] (P01).

[...] acho que falta a gente ter um pouco mais de propaganda sobre a questão do câncer de colo do útero e do seu diagnóstico [...] eu acho que perpassa sobre essa questão da informação, da propaganda mesmo, do conhecimento da importância do exame e da questão do diagnóstico precoce de câncer de colo de útero [...] (P10).

Não obstante, observa-se acentuadamente na fala do profissional P10 certo apelo à veiculação de informações midiáticas acerca "do câncer de colo de útero e do seu diagnóstico”. Essa fala encontra ressonância como estratégia populacional capaz de atingir grande parcela da população na transmissão das informações supramencionadas, assim como para abarcar mulheres que porventura ainda não tenham tido contato com os serviços de saúde para a realização do exame, característica das mulheres elegíveis deste estudo.

Contudo, salienta-se que tal estratégia não suprime a responsabilidade do profissional de saúde em realizar uma abordagem educativa nas consultas individuais ou em atividades coletivas com as mulheres, perpassando as competências profissionais para realização das práticas assistenciais, a compreensão do processo saúde-doença que envolve o câncer, a compreensão dos sentimentos da mulher em relação ao exame, da situação social, econômica e cultural das mesmas, bem como da organização dos serviços de saúde (OLIVEIRA; PINTO, 2007). 
Notou-se também que algumas mulheres apontaram o exame como forma de descobrir e prevenir moléstias, e não como forma de cuidado à saúde sexual de forma geral, refletindo concepçôes reducionistas pautadas na doença. Além disso, essas mulheres não distinguem apropriadamente a coleta de material para o exame preventivo do exame ginecológico, associando a realização do mesmo de forma curativa, advinda muitas vezes de queixas ginecológicas com sintomatologias específicas, ou até mesmo à falta de sintomas. Essas falas são semelhantes às encontradas em outros estudos (JORGE et al., 2011; LUCENA, 2011; RICO; IRIART, 2013; SOUSA et al., 2008).

[...] não tenho precisão, eu não sinto nada no útero, minhas dores é só nas pernas mesmo [...] (U10).

[...] acho que não preciso desse exame aí não [...] eu não sinto nada não. (U11).

Alguns profissionais de saúde também ratificaram esta posição:

[...] outras não têm essa preocupação, falam... "Ah, não fiz, por mim, estou sem homem, então, pra que eu vou fazer?” As mulheres vinculam muito o exame à questão da sexualidade e das DSTs[...] Depois que tem uma leucorréia, ou alguma outra coisa que elas resolvem fazer o preventivo [...] (P01)

[...] então eu creio que é o fato da ausência de sintomas na fase inicial do câncer, nos estágios precursores do câncer. Como não tem nenhum sintoma, então a mulher não procura, né? [...] (P08).

Interessante notar, ainda, que emergiu na fala do profissional P01 a relação entre câncer e sexo como uma barreira que limita as mulheres de realizarem o exame de rastreamento do colo do útero, sendo esta barreira também documentada em outro trabalho (PETER; NAVKIRAN, 2009). Contudo, neste estudo, nada foi mencionado sobre os outros fatores predisponentes, como tabagismo, nuliparidade, história familiar, condições socioeconômicas e de higiene (DAVIM et al., 2005; FERNANDES et al., 2009; SANTOS; MACÊDO; LEITE, 2010), denotando, de certa forma, desresponsabilização da mulher com sua saúde e atribuindo supremacia a este fator.

Por outro lado, outro aspecto que merece destaque é que a fala articula-se fortemente à dimensão de gênero e é reforçada por práticas de promoção da saúde voltadas para a saúde sexual e reprodutiva feminina - ou seja, para a associação do útero como identidade feminina e especialmente como função materna (RICO; IRIART, 2013). 


\section{Categoria 2: Sentimentos negativos diante do exame}

Os modos de cuidado dos estados de saúde e de doença são experienciados por cada um de forma particularizada e fundamentada em suas trajetórias de vida. Sentimentos negativos relacionados a determinadas práticas de cuidado à saúde, como a realização do exame de prevenção do colo do útero, também apresentam tal vinculação.

Experiências restritivas no âmbito da sexualidade, falta de informação acerca da anatomofisiologia feminina, conhecimento deficitário sobre o cuidado acerca da saúde sexual, concepções do câncer como sinônimo de perda de controle da sua própria vida e de proximidade da morte, experiências de violência, falta de acesso e falta de comunicação/explicação acerca do exame nos serviços de saúde, são alguns dos fatores que contribuem para a externalização de sentimentos negativos como vergonha, medo e constrangimento por parte das mulheres em relação ao exame Papanicolau (OLIVEIRA; PINTO, 2007; RICO; IRIART, 2013).

A vergonha de se submeter ao exame Papanicolau foi um dos sentimentos mais recorrentes relatados pelas mulheres participantes da pesquisa, assim como em outros estudos (MENDONÇA, 2011; WILIANS; AMOATENG, 2012). A exposição do corpo no momento do procedimento remete a questôes referentes à sexualidade, podendo aflorar sentimentos negativos de bloqueio e conflito para algumas mulheres. E estas resistências são geralmente externadas como vergonha e constrangimento.

[...] eu não realizo o exame porque eu acho um exame muito esquisito. [...] acho que deve ser muito constrangedor, pela forma como ele é feito [...] (U08).

[...] eu não faço o exame porque tenho vergonha de "abrir as pernas" e mostrar a parte íntima para os médicos [...] (U09).

O sentimento de vergonha corresponde, portanto, à não aceitação decorrente do processo psicológico de ser flagrado fora dos padróes aceitos e valorizados pela sociedade, onde o outro é tido como avaliador numa posição de juízo alheio (DUAVY et al., 2007).Para alguns profissionais de saúde, a não realização do exame Papanicolau perpassa por questões também relacionadas ao pudor, o que reforça a forte presença dessa barreira no âmbito das mulheres.

[...] algumas se sentem envergonhadas de virem [...] (P04).

[...] então acho que está mais relacionado mesmo a essa questão do pudor, a vergonha [...] (P06). 
A vergonha e o pudor também podem ser expressos pelas mulheres como uma sensação de impotência, desproteção e falta de domínio sobre o próprio corpo, os quais são proporcionados através da posição ginecológica indispensável para a realização do exame (FERREIRA, 2009). Observou-se, ainda, que o sentimento de vergonha apresenta grande impacto se o exame tiver que ser realizado por um profissional do sexo masculino, diferentemente do que se espera quando o examinador é do sexo feminino. Tal posição pode ser explicada por uma possível conotação de cumplicidade entre seres semelhantes, portadores de uma mesma anatomia e talvez com as mesmas vivências de privação do corpo, de quem se pode esperar compreensão (JORGE et al., 2011; SOUSA et al., 2008).

[...] se fosse um médico eu teria vergonha por ser homem, mas fora isso eu não tenho vergonha não [...] (U01).

[...] tenho só um pouquinho de vergonha, principalmente se for homem que for fazer [...](U03).

Ademais, as relações de gênero historicamente construídas na sociedade definem as práticas em relação ao corpo e à sexualidade, de maneira que a exposição da genitália feminina e a manipulação das mesmas pelo profissional de saúde podem gerar vergonha e constrangimento nas mulheres, por se tratar de ações consideradas moralmente incorretas, levando-as muitas vezes, por este motivo, a não realizarem o exame Papanicolau, principalmente quando o profissional é do sexo masculino.

Outro sentimento negativo que emergiu na fala das mulheres e de profissionais, além da vergonha, foi o medo. O medo é uma inquietação angustiosa que se manifesta frente a um risco ou um mal real ou imaginário, que só desaparece com o fim da situação ameaçadora (OLIVEIRA; PINTO, 2007; SOUSA et al., 2008).

[...] o povo queixa demais que dói, aí isso também me deixa com medo [...] (U06).

[...] às vezes eu fico com um pouco de medo também, tem gente que fala que dói [...]. (U11).

[...] quando ela nunca fez, a vizinha, a irmã diz que é horrível, que vai puxar o útero, inventa mil histórias e aí ela vai ficando com mais medo[...] (P05).

Observou-se que boa parte das mulheres que nunca realizou o exame Papanicolau possui ideias preconcebidas a respeito do mesmo, ideias são elaboradas a partir de experiências negativas passadas pelo entorno feminino, ou seja, por outras mulheres. Portanto, essas interpretações surgem como resultado 
da associação entre a carência de informações veiculadas pelos serviços de saúde e o que é difundido na comunidade acerca do exame Papanicolau.

Interessante salientar que, embora não destacado pelas mulheres, a fala do profissional P09 apontou o sentimento das mesmas como sinônimo de medo do resultado do exame, o qual pode ser por ocasião do diagnóstico de uma doença sexualmente transmissível (DST) ou do próprio câncer, este ainda estigmatizado na sociedade moderna por configurar-se como uma doença crônica, podendo em caso extremo comprometer a vida.

[...] não fazem porque tem medo, tem vergonha, tem medo de saber o resultado porque pode dar algum problema sério [...] (P09).

\section{Categoria 3: Falta de atitude}

A falta de interesse por parte de algumas mulheres, em buscar a utilização de medidas preventivas, foi relatada em alguns depoimentos como principal barreira para a realização do exame Papanicolau, uma vez que interfere diretamente nos aspectos relacionados com as atitudes e práticas das mulheres frente ao exame.

[...] é falta de interesse mesmo. Eu sei que preciso fazer urgentemente, mas eu tenho é preguiça mesmo [...] (U04).

[...] eu nunca fiz por descuido mesmo, "falta de vergonha na cara". Assim, é descuido, porque eu vou enrolando, enrolando, enrolando e nunca faço [...] (U11).

[...] eu nunca fiz o exame não, tanto por falta de tempo quanto por falta de interesse, a gente acha sempre que com a gente nunca vai acontecer, né? Então acaba sendo relapsa [...] (U14).

Assim como em estudo realizado em Porto Alegre-RS, o descuido com a própria saúde foi um dos principais motivos apontados pelas participantes da pesquisa para a não realização do exame. Constatou-se que muitas mulheres só procuram assistência à saúde quando já estão doentes, sugerindo que isso acontece devido ao maior enfoque dado ao tratamento e não à prevenção das doenças, por influência do modelo biomédico ainda predominante em nosso país (PERETTO;DREHMER; BELLO, 2012). Desse modo, a resolutividade das açôes coletivas e individuais, na perspectiva deste enfoque, tende a ser questionada, tanto pelo fato de ainda se fazer presente na própria Estratégia de Saúde da Família, eleita como estratégia com potencial para reorientar modelos tecnoassistenciais em saúde, como pelo fato de direcionar-se preponderantemente 
a responder às demandas somente das pessoas que procuram pelos serviços de saúde (FAVORETO, 2006).

Soma-se a isto, o fato de muitas mulheres tratarem o câncer de colo do útero como uma doença distante do seu contexto de vida, favorecendo a falta de atitude e a não realização do exame Papanicolau. $\mathrm{Na}$ maioria das vezes, esse conhecimento consensual só é mudado quando elas mesmas ou pessoas próximas são acometidas pela doença.

Esta falta de atitude por parte das mulheres, em buscarem os serviços de saúde para realização do exame de rastreamento do câncer de colo uterino, também foi uma das barreiras apontadas pelos profissionais de saúde.

[...] as pessoas têm conseguido agendar com facilidade, então acredito que seja mais uma questão de atitude da população [...] (P07).

[...] comodismo de algumas por achar assim "Não vai acontecer comigo". Acesso ao serviço todas tem. A gente não tem dificuldades em relação a isso [...] desleixo [...] (P06).

Para mim as barreiras estão relacionadas à própria mulher, é falta de cuidado próprio, falta de amor próprio [...] (P12).

Os profissionais P07 e P06 fazem alusão a um serviço que não oferece impedimentos em termos de acesso à realização do exame Papanicolau, polarizando nas mulheres a responsabilidade pela não realização do mesmo. Em uma primeira análise, as falas das usuárias encontram eco nas falas dos profissionais. Contudo, a adesão ao exame transcende apenas a oferta do serviço, pois inclui a necessidade de uma abordagem que perpasse a problematização dos conceitos de saúde-doença das mulheres e dos profissionais, de vulnerabilidade ou susceptibilidade, da identificação de fatores de risco no estilo de vida, do cultivo de hábitos e atitudes promotores de qualidade de vida, do desenvolvimento de consciência para o autocuidado, de esclarecimentos, suporte social e emocional (MOREIRA; SANTOS; CAETANO, 2009). Tais elementos necessitam ser repensados e incorporados em todas as práticas voltadas para a saúde da mulher e não apenas no dia destinado ao exame.

\section{Categoria 4: Aspectos relacionados aos serviços de saúde}

Além das dificuldades intrínsecas de cada mulher para a realização do exame de prevenção do câncer de colo do útero, existem aquelas relacionadas com a estruturação dos serviços de saúde, as quais foram apontadas por mulheres e 
profissionais de saúde. A dificuldade de marcar consulta por falta de vaga foi referenciada como uma barreira institucional para o acesso ao exame Papanicolau.

[...] eu nunca fiz porque nunca consegui marcar, porque quando vou no posto a mulher fala que não está marcando porque é final do mês, ai quando eu volto em outra data, ela fala que não tem mais vaga [...] (U01).

[...] eu já procurei algumas vezes para marcar, e não consegui, fui marcar de manhã e ai já tinha esgotado as vagas, e aí vou enrolando, deixo de lado e não faço. (U03).

Conquanto o acesso aos serviços de saúde tenha sido reportado pelo senso comum como mera expansão da oferta, outras interpretações permeiam também a compreensão da satisfação das necessidades em saúde, fundamentada em um enfoque teórico que é a equidade horizontal, a qual pressupóe igual acesso para igual necessidade de saúde (SANCHO; SILVA, 2013). Neste caso, pode-se depreender que, além de problemas relacionados com o acesso e oferta de vagas para realização do Papanicolau, as mulheres não tiveram suas necessidades de saúde atendidas, o que poderia ser representado em um sentido mais estrito pelo cuidado da sua saúde sexual.

Assim, as barreiras de acessibilidade e oferta associadas à organização dos serviços configuram-se como condicionantes do processo de saúde-doença para o câncer de colo do útero, transcendendo o controle das mulheres, as quais se autoclassificariam "desculpadas" pela não realização do exame devido a fatores externos à vontade delas (RICO; IRIARTE, 2013). Estudos apontam que as mulheres com maior risco para o desenvolvimento de lesóes cervicais são aquelas com menor acessibilidade aos serviços e programas em saúde (OLIVEIRA; PINTO, 2007; RICO; IRIARTE, 2013).

Além do acesso, alguns profissionais de saúde revelaram problemas relacionados com a sobrecarga de trabalho, o que naturalmente reflete na oferta insuficiente de vagas para atender a população.

[...] eu trabalho numa área que possui 14 microáreas, então assim, uma área muito extensa, ai no caso tem eu que faço, porque a médica, como tem vários outros programas, vários atendimentos, a área é muito grande, aí a gente definiu que a realização do exame preventivo ficaria comigo. E a gente não tem tantos turnos disponíveis assim para preventivo [...] (P02).

[...] às vezes o que falta mesmo é vaga. Só quem faz o preventivo no momento sou eu, mesmo quando a gente tem médico na equipe, eles acabam não querendo muito fazer o preventivo [...] (P11). 
Alguns profissionais apontaram, ainda, como barreira organizacional para a realização do exame Papanicolau, a falta de espaço, materiais e recursos.

[...] muitas vezes falta material em processo licitatório, a gente já passou por isso [...] (P01).

[...] nós só temos duas macas ginecológicas disponíveis. Então, ainda que tivesse mais profissional disponível para realizar o exame, ficaria em questão a falta da maca e a questão do espaço também [...] (P02).

É necessário que os serviços de saúde estejam equipados e organizados para realizar o exame regularmente, para que grande parcela da população feminina seja rastreada e beneficiada pelo programa de prevenção do câncer cérvicouterino. De acordo com as estratégias de implantação do Programa de Atenção Integral à Saúde da Mulher, para que este tenha uma resolutividade satisfatória, é necessário um preparo técnico tanto do pessoal envolvido diretamente na prestação de serviço quanto do pessoal encarregado das funções de supervisão, organização e coordenação programática (MADUREIRA, 2003).

Além dos motivos supracitados, outros estudos também evidenciam a presença de barreiras geográficas, como a localização do serviço de saúde, sua distância em relação aos usuários, dificuldades de transporte e, principalmente, a presença de barreiras organizacionais, como burocracia, tempo gasto na marcação de consulta, tempo de espera para o atendimento, má articulação entre os serviços de saúde na prestação da assistência nos diversos níveis de atenção (JORGE et al., 2011; OLIVEIRA; PINTO, 2007; RICO; IRIARTE, 2013).

A sinergia obtida pela percepção dos profissionais e das usuárias presente nesta categoria promove uma reflexão acerca da necessidade de priorizar as mulheres faltosas em relação ao exame, especialmente aquelas com o perfil das entrevistadas neste estudo (jovens, com tempo de frequência elevada na unidade de saúde, com um início bastante precoce da atividade sexual, em idade fértil e que nunca realizaram o Papanicolau), pois encontram-se em maior zona de risco para o desenvolvimento do câncer cérvico-uterino.

Em contrapartida observa-se, em alguns depoimentos dos profissionais, que a oferta do exame Papanicolau é tida como fator facilitador do processo de adesão ao mesmo, o que contradiz o exposto por algumas mulheres.

[...] Acesso ao serviço todas tem, a gente não tem dificuldades em relação a isso [...] (P06).

[...] As pessoas têm conseguido agendar com facilidade [...] (P07).

[...] Hoje acho a oferta muito boa [...] (P08). 
O possível antagonismo entre as falas das mulheres e a de alguns profissionais traz a tona mais uma vez, que o acesso não é somente interferido pelas dimensões da oferta e demanda, mas sim pela indução à constituição de uma rede de atenção à saúde capaz de responder às necessidades sociais e de saúde dos indivíduos (SANCHO e SILVA, 2013).

\section{Categoria 5: Inserção no mercado de trabalho}

A inserção feminina no mercado de trabalho representou, para as mulheres, uma grande conquista, uma vez que este processo constituiu um marco na busca pela igualdade entre os gêneros. A despeito dos avanços observados e da redefinição do papel da mulher na sociedade ao longo do tempo, as repercussões geradas na qualidade de vida da população feminina nem sempre foram positivas (BENITES; BARBARINI, 2009).

A sobreposição das atividades laborais associadas ao cuidado familiar tem sobrecarregado a mulher e dificultado sua adesão às práticas preventivas, uma vez que elas vivenciam a incompatibilidade de horários entre jornada de trabalho e o expediente ofertado pelos serviços de saúde, e assim, deixam de realizar o exame Papanicolau:

[...] eu trabalho também, né? Então não dá tempo de ir lá fazer. Eu saio do trabalho $14 \mathrm{~h}$, mas daqui que vou tomar banho, arrumar para ir, já passou do horário, aí eu não faço (U09).

[...] hoje a mulher trabalha muito, então às vezes deixa a saúde de lado porque o trabalho exige muito[...] hoje a gente associa também a essa questão que a mulher hoje é multifuncional, né? Então isso talvez esteja atrapalhando um pouco ela nessa questão do autocuidado [...] (P06).

[...] a mulher em idade fértil, é a mulher que está inserida no mercado de trabalho, ai não dá tempo, a patroa não dispensa [...] não sei se estão deixando essa vida corrida após a inserção no mercado de trabalho atrapalhar o seu cuidado em relação à saúde (P08).

Compreende-se, portanto, que a inserção da mulher no mercado de trabalho e a correria do dia a dia, ao mesmo tempo em que representa conquista em termos sociais, nem sempre satisfatória do ponto de vista econômico, também constitui fator interveniente para a não realização do exame Papanicolau. No que se refere à oferta de serviços em horários que abarquem a disponibilidade, observou-se que a atenção primária à saúde não se encontra preparada para atendê-las, o que acaba por dificultar o acesso. Desta forma, depreende-se a importância de se 
propor programações alternativas e flexibilizadoras no âmbito da ESF, a fim de

contemplar integralmente as necessidades de saúde não só deste grupo, mas de toda a classe economicamente ativa.

\section{Considerações finais}

O presente estudo buscou compreender a complexidade do fenômeno que envolve a não realização do exame Papanicolau segundo a percepção das usuárias e dos profissionais da Estratégia de Saúde daFamília. A compreensão de tal fenômeno consiste no primeiro passo ante a definição de estratégias de intervenção adequadas à realidade da população feminina em questão.

Conhecimento insuficiente acerca do exame Papanicolau e da sua finalidade; sentimentos negativos diante do exame como vergonha, medo, constrangimentos; falta de atitude; aspectos relacionados aos serviços de saúde como acesso limitado, oferta reduzida e a inserção das mulheres no mercado de trabalho constituíram barreiras à realização do Papanicolau, contribuindo para as mulheres se tornarem mais vulneráveis ao câncer cérvico-uterino e, deste modo, impedindo o estabelecimento de ações eficazes no âmbito da prevenção.

A congruência e incongruência de significados emergidos nos discursos das mulheres e dos profissionais de saúde acerca das barreiras para a realização do exame Papanicolau possibilitará o direcionamento de um caminho estratégico que leve à transformação da prática assistencial do profissional de saúde e ao atendimento das reais necessidades dessas mulheres. Implica também aproximar a transformação social que envolve o comportamento dessas mulheres em relação à prevenção, a qual só é possível por meio da modificação do estilo de vida, de práticas educativas que forneçam informações culturalmente relevantes e cientificamente fundamentadas acerca do exame e da enfermidade que ele previne, do estabelecimento de laços vinculares e do acolhimento, da reorganização da assistência às mulheres, do estabelecimento de intervenções mais humanizadas, equitativas e focadas em eliminar as barreiras e iniquidades no acesso e utilização dos serviços preventivos, respeitando as realidades intrínsecas de cada mulher.

Por fim, conclui-se que não basta apenas garantir o acesso ao exame Papanicolau nos serviços de saúde, tampouco emitir informações acerca do mesmo. Antes, é necessário garantir que a mulher tenha acesso a essas informações, e que estas 
sejam adequadas a sua realidade histórica, social e de saúde, a fim de que sejam compreensíveis e factíveis. Dessa forma, acredita-se que as mulheres resistentes ao exame Papanicolau serão levadas a refletirem acerca dos seus saberes e se conscientizarão da verdadeira importância do exame, para que assim, possam efetivamente realizá-lo. ${ }^{1}$

\section{Referências}

AMORIM, V. M. S. L. et al. Fatores associados à não realização do exame de Papanicolaou: um estudo de base populacional no Município de Campinas, São Paulo, Brasil. Cad. Saúde Pública. Rio de Janeiro, v. 22, n.11, p. 2329-2338, 2006.

BENITES, A. P. de O.; BARBARINI, N. Histórias de vida de mulheres e saúde da família: algumas reflexões sobre gênero. Psicologia e Sociedade. Santa Catarina, v. 21, n. 1, p. 16-24, 2009.

BRASIL. Ministério da Saúde. Prevenção do câncer do colo do útero. Manual técnico:profissionais de saúde. Brasília, 2002.

BRASIL. Ministério da Saúde. Sistema de informação do câncer do colo do útero. Disponível em: <http:/www2.inca.gov.br/wps/wcm/connect/acoes_programas/site/home/nobrasil/ programa_nacional_controle_cancer_colo_utero/indicadores>. Acesso em: 01 out. 2013.

BRENNA, S. M. F. et al. Conhecimento, atitude e prática do exame de Papanicolaou em mulheres com câncer de colo uterino. Cad. Saúde Pública. Rio de Janeiro, v. 17, p.909-14, 2001.

CRUZ, L. M. B.; LOUREIRO, R. P.A Comunicação na Abordagem Preventiva do Câncer do Colo do Útero: importância das influências histórico-culturais e da sexualidade feminina na adesão às campanhas. Saúde Sociedade, São Paulo, v.17, n.2, p.120-131, 2008.

DAVIM, R. M. B. et al. Conhecimento de mulheres de uma Unidade Básica de Saúde da cidade de Natal/RN sobre o exame de Papanicolau. Revista Escola de Enfermagem USP, São Paulo, v.39, n.3, p.296-30, 2005.

DUAVY, L. M. et al. A percepção da mulher sobre o exame preventivo do câncer cérvicouterino: estudo de caso. Ciência \& Saúde Coletiva, Rio de Janeiro, v. 12, n. 3, p. 733-742, 2007. FAVORETO, C. A. O. A velha e renovada clínica dirigida à produção de um cuidado integral em saúde. In: PINHEIRO, R.; MATTOS, R. A. de. Cuidado: as fronteiras da integralidade. São Paulo:Hucitec,2004, p. 205-219.

FERNANDES, J. V. et al. Conhecimentos, atitudes e prática do exame de Papanicolaou por mulheres no Nordeste do Brasil. Rev.Saúde Pública, São Paulo, v.43, n.5, p. 851-8, 2009.

FERREIRA, M. L. da S. M. Motivos que influenciam a não-realização do exame dePapanicolaou segundo a percepção de mulheres. Esc. Anna Nery Rev. Enfermagem, Rio de Janeiro, v. 13 n. 2, p. 378-384, 2009. 
FONTANELLA, B. J. B.; RICAS, J.; TURATO, E. R. Amostragem por saturação em pesquisas qualitativas em saúde: contribuiçōes teóricas. Cad. Saúde Pública, Rio de Janeiro, v. 24 , n. 1, p. $17-27,2008$.

JORGE, R. J. B. et al. Exame Papanicolau: sentimentos relatados por profissionais de enfermagem ao se submeterem a esse exame. Ciência \& Saúde Coletiva, Rio de Janeiro, v. 16, n. 5, p. 2443-2451, 2011.

LUCENA, L. T. et al. Fatores que influenciam a realização do exame preventivo do câncer cérvico-uterino em Porto Velho, Estado de Rondônia, Brasil. Revista Pan-Amazônica de Saúde,Belém do Pará, v. 2, n. 2, p. 45-50, 2011.

MADUREIRA, A. B.A saúde como direito: o exame preventivo de câncer de colo uterino sob o olhar da faltosa.103 p. Dissertação (Mestrado em Enfermagem) - Programa de Pós-Graduação em enfermagem da Fundação Universidade Federal do Rio Grande. Rio Grande, 2003.

MELO, M. C. S. C.et al. O enfermeiro na Prevenção do Câncer do Colo do Útero: o Cotidiano da Atenção Primária. Revista Brasileira de Cancerologia, Rio de Janeiro, v. 58, n.3, p.389-398, 2012.

MENDONÇA, F. A. da C.et al. Prevenção do câncer de colo uterino: adesão de enfermeiros e usuárias da atenção primária.Rev. Rene, Fortaleza, v. 12, n.2, p.261-70, 2011.

MINAYO, M. C. de S.Técnicas de análise do material qualitativo. In: . O desafio do conhecimento. Pesquisa qualitativa em saúde.São Paulo: Hucitec, 2007, p.303-360.

MOREIRA, A. K. de F.; SANTOS, Z. M. de S. A.; CAETANO, J. A.Aplicação do modelo decrenças em saúde na adesão do trabalhador hipertenso ao tratamento. Revista de Saúde Coletiva, Rio de Janeiro, v. 19, n. 4, p. 989-1006, 2009.

NUNES, A. A. et al. Resolubilidade da Estratégia de Saúde da Família e Unidades Básicas de Saúde Tradicionais: Contribuições do PET-Saúde. Revista Brasileira de Educação Médica, Rio de Janeiro, v.36, n. 1, p. 27-32, 2012.

OLIVEIRA, M. M. H. N.et al. Cobertura e fatores associados à não realização do exame preventivo de Papanicolaou em São Luís, Maranhão. Rev. Brasileira de Epidemiologia, São Paulo, v. 9, n.3, p.325-34, 2006.

OLIVEIRA, M. M.; PINTO, I. C. Percepção das usuárias sobre as ações de prevenção do câncer do colo do útero na Estratégia de Saúde da Família em uma Distrital de Saúde do município de Ribeirão Preto, São Paulo, Brasil. Rev. Bras. Saúde Materno-Infantil, Recife, v.7, n.1, p.31-38, 2007.

PERETTO, M.; DREHMER, L. B. R.; BELLO, H. M. R.O não comparecimento ao exame preventivo do câncer de colo uterino: razôes declaradas e sentimentos envolvidos. Cogitare Enfermagem, Paraná, v.17, n.1, p. 29-36, 2012.

PETER, N. A.; NAVKIRAN, K. S. Cervical cancer screening among college students in Ghana: Knowledge and health beliefs. Int. J.GynecolCancer, v. 19, n. 3, p. 412-416, 2009. 
RICO, A. M.; IRIART, J. A. B.: “Tem mulher, tem preventivo”: sentidos das práticas preventivas do câncer do colo do útero entre mulheres de Salvador, Bahia, Brasil. Caderno de Saúde pública, Rio de Janeiro, v. 29, n. 9, p. 1763-1773, 2013.

SANCHO, L. G.; SILVA, N. E. K. Descortinando o acesso aos serviços de saúde na perspectiva da interdisciplinaridade: debate de idéias. Physis: Revista de Saúde Coletiva, Rio de Janeiro, v. 23, n. 2, p. 371-391, 2013.

SANTOS, M. S.; MACÊDO, A. P. N.; LEITE, M. A. G. Percepção de usuárias de uma Unidade de Saúde da Família acerca da Prevenção câncer do colo do útero. Rev. APS, Juiz de Fora, v. 13, n. 3, p. 310-319, 2010.

SILVA, S. E. D. et al. Esse tal Nicolau: representações sociais de mulheres sobre o exame preventivodo câncer cérvico-uterino. Rev. Escola de Enfermagem USP, São Paulo, v. 44, n. 3, p. 554-560, 2010.

SOUSA, I. G. da S.et al. Prevenção do câncer de colo uterino: percepções de mulheres ao primeiro exame e atitudes profissionais. Rev. RENE, Fortaleza, v. 9, n. 2, p. 38-46, 2008.

WILLIAMS, M.; AMOATENG, P. Knowledge and beliefs about cervical cancer screening among men in Kumasi, Ghana .Ghana Medical Journal,Ghana,v.46, n. 3, p. 147-151, 2012.

\section{Nota}

${ }^{1}$ R. P. Aguilar e D. A. Soares participaram da concepção do projeto; análise e interpretação dos dados; redação do artigo; e aprovação final da versão a ser publicada. A pesquisa foi financiado pelas próprias autoras. Não existem conflitos de interesse. 


\section{Abstract}

Barriers to pap smear: prospects for users and professionals of the Family Health Strategy in Vitória da Conquista-BA

The cervical cancer has high prevalence and mortality rates, and the main strategy of screening is the pap smears. Joining the examination is still far from the recommended coverage. This study aimed to understand the barriers that lead women of childbearing age in the city of Vitoria da Conquista-BA not to perform pap smears in the perspective of the women and health professionals. Descriptive qualitative study was exploratory, with data collected between April-May 2014, with semi-structured interviews with health professionals 12 and 14 users. Thematic categorical analysis, which revealed the following barriers for not undergoing the test was applied: insufficient knowledge, negative feelings, lack of attitude, aspects linked to health care and inclusion of women in the labor market services. The congruence and incongruence of meanings that emerge allow a path that transforms the practice of health care and the needs of those professional women.

Key words: vaginal smears; uterine cervical diseases; family health. 